\title{
Corruption in Romania-Public vs. Private Sector
}

\author{
Simona Vasilache, Roxana Gazdaru, Mihaela Sava \\ Bucharest University of Economic Studies, Bucharest, Romania \\ Email: simona.vasilache@gmail.com
}

How to cite this paper: Vasilache, S., Gazdaru, R., \& Sava, M. (2021). Corruption in Romania-Public vs. Private Sector. Open Journal of Business and Management, 9, 928-954.

https://doi.org/10.4236/ojbm.2021.92050

Received: August 11, 2020

Accepted: March 28, 2021

Published: March 31, 2021

Copyright $\odot 2021$ by author(s) and Scientific Research Publishing Inc. This work is licensed under the Creative Commons Attribution International License (CC BY 4.0).

http://creativecommons.org/licenses/by/4.0/

\begin{abstract}
This research paper reviews the topic of corruption, in a comparative approach of the public and private sector in Romania, considering the wider background of the European Union. Based on the findings of a survey performed by the authors, we advance strategies and recommendations for both the public and business management, in order to align their views with the premises of ethical administration.
\end{abstract}

\section{Keywords}

Ethics, Corruption, Public Management, Business Administration

\section{Introduction}

\subsection{Ethical Management, Ethics Management and Organizational Ethics}

From any historical perspective, one would like to perform this present analysis. It is a fact that the demise of socialism and communism in Central and Eastern European (CEE) countries was the most important and dramatic change in the last half century (Bratianu \& Vasilache, 2009). Corruption in post-communist Romania-that the private use of public office-was one of the hottest topics of political dispute. It was created to confront this phenomenon, the National Anticorruption Department. Underlying strategy-if there was any-was based on at least the next two tacit assumptions: 1) fighting corruption is a phenomenon purely legal; 2) the DNA to be focusing solely on "the big corruption" on catching "big fish". Both seem false premise. Corruption is, in fact, a moral phenomenon (and only legal side: he was sanctioned legal because it is immoral); accordingly, we should expect that there to be forms of struggle against corruption that are not based on procedures and penalties typically legal, but the 
methods strictly ethical, such as creating a culture of institutional anti-corruption or educating intra-institutional character. In which department they manage them and put them into work? It looks like none. Such a characteristic obtuseness is not only Romania:

"Did all the nations of the world embrace management strategies ethically? Yes, but primarily in terms of combating corruption laws, rules and regulations. The limits of this approach are obvious. It reduces ethical behaviour in its minimal form (not violate the law or regulations) and encourages a narrow, legalistic definition of acceptable behaviour" (Menzel, 2007).

The European Commission sees things the same way legalistic. The monitoring report of Romania from 2016 (Commission reports on progress in Romania under the Co-operation and Verification Mechanism) says: "The existing legislation in the fight against corruption must be applied rigorously and corruption in the structures of law enforcement has appealed strongly. Moreover, there must be an implementation totally transparent, responsible and strict all codes of ethics and professional ethics for civil servants, accompanied by a consistent application of sentencing to send a strong message of deterrence to corruption". Therefore, laws and courts should be with ethical codes and they should be thrown in the fight against corruption but without being coupled with legal action ("criminal penalties") to make them more convincing sanctions. The question is: are there no other measures for the implementation of codes of ethics outside of legal punishment? Moral education and formation of organizational culture have somehow distinct from that of specific law enforcement? For lawyers twice is not the answer; and this text was written by lawyers. Like most other professionals, they think to understand and apply legal rules must prepare for several years in a good college while to understand and apply a moral rule you only need at most common sense. Hence facto disregard of morals by its passage constant alternatively, without recognizing, of course, this. In this highest form of ignorance on the status of ethics lies the root of evil (Jeurissen, 2005).

In Japan, however, the leaders of this country seem more subtle. Parliament passed in 1999 a law on the morality of public services that established by creating an ethic of national administration, appointed by the Government, created supervisors on ethical issues in all ministries and agencies, promulgated a code of ethics for civil servants and called for the introduction of ethics in local government management. In other words not only created codes of ethics, but also took specific measures for their implementation. Ethics Committee aims to prepare ethical standards in state institutions, to take disciplinary measures against violation of moral rules by government employees and prepare much diversified training programs and create ethical institutional culture for all ministries. Both the code and the work of committees and supervisors are focused now on the issue of accepting favours by public officials-the problem which, it seems, is and there's a social disease chronic (Rossouw \& van Vuuren, 2003). So we see that the so-called "small corruption" not it is countered only by laws and legal 
institutions; and not one single case of Japan. Let's go back to Romania where such steps would be considered, certainly naive.

This paper addresses the management of all elements related to the moral life of an organization, be it commercial company, hospital or university-to the extent that the moral life of an organization is something taken seriously. Not to be confused with ethical management "ethical management" (management ethics), i.e. the study of ethical issues raised by the various forms of management-financial management, personnel, strategic management, quality management etc. "Ethics management" is often considered as equivalent to "business ethics" (business ethics). Management is more general and ethics is different. He must also be distinguished from "organizational ethics" in the broad sense, i.e. the ethical analysis of organizations to provide clarification and guidance normative ethics, using for these different ethical theories. The latter category includes business ethics, advertising ethics, ethics restructuring companies, etc. (Boylan, 2013).

Recent decades have insistently imposed in the public consciousness the importance of taking into account the ethical dimension of life organizations. Codes of ethics, ethics committees, auditing ethics, ethical education of personnel, techniques for creating an institutional culture of moral nature seeking "packs tools" decision ethic-all these have become the realities of increasingly widespread-among other things because they were imposed politically and in many countries, received a formalization and legal force. It is true that people do not internalize their habits has reached spectacular, but the process is ongoing. "Institutionalization of ethics" is a new reality for which we must prepare meeting.

After a romantic era in which philosophers morals ignored almost completely applications and the managers did not understand that it's their connection to ethics or, at best, were convinced that to control life ethics organizations, if there is such a thing, do not need a special professional competence, here are the various "ethical content" of organizations have begun to clutter our consciences and require us to theoretical refinements, simply generating a new branch management-ethical management.

Management ethics, "as one of the disciplines of management, dealing with draft those leading tools that help develop ethics of an organization as well as those methods that can be used to determine in which direction should develop organizations. Management Ethics involves the description and analysis of the ethical current, determining the desired situation and the decision on measures to be taken to achieve it, in harmony with the other forms of management. Management of ethics is the result of impregnating more visible organizations with responsibility," seen but not as a decoration, but as a "necessary condition of their existence." And an organization demonstrates moral responsibility when their interests are subordinated to the interest of society (Arbogast, 2013).

According to Ronald Jeurissen, ethical management aims to improve deci- 
sion-making processes, procedures and organizational structures, so that the activities of the organization to be as much about ethical principles. The instruments used are ethical codes, ethical audits and other "strategies" to lead the organization on the path of respecting morality (Jeurissen, 2005).

After Donald Menzel, ethical management and control was not to penalize staff behaviour or reflection on ethics in the workplace. He's rather all actions taken by managers to foster an ethical conscience and sensibility to penetrate into all aspects of organizations. He is, in short, promoting and maintaining a strong ethical culture at work (Menzel, 2007).

The question might now ask would be: given that ethical management definitions vary, what form it may take? Experience in the field is short (two or three decades), but nonetheless have been proposed several models of "ethical progress of organizations." Opinions are different and in this case, although there are enough points of convergence. Some authors speak of four stages in the evolution of management ethics: the initial stage of awareness of ethical, followed by stage reasoning ethical (procedures and criteria for decision-making), and stage action and, finally, the state leadership's ethical (promote employment and ethical culture). Others deny the idea of evolution and prefer a comprehensive approach, with different strategies that complement each other (Trevino \& Nelson, 2014).

\subsection{Historical Evolution}

D. Menzel, for example, believes that to build "organizations of integrity" we are forced to rely on management ethics can know four types of strategic approach. The first strategy is based on compliance (compliance), that the formulation and enforcement of ethical rules in the organization. The second is the cost inclusion strategy, a vision that treats unethical actions as a cost factor to be reduced, minimized or eliminated. The third is learning strategy, where the focus is placed on ethical training processes and assimilation of ethical provisions. Finally, the fourth strategy is to create an organizational culture of moral nature; this is considered the most promising of all, assuming you also. Interesting is the list "tools available to managers ethics" tools that could build organizations of integrity; by empirical verification of this list, the author makes an analysis of the state of ethical management in many organizations of public administration in the US. These tools are:

- A collective leadership morally exemplary;

- Practicing ethical training organization;

- Codes of ethics;

- Professional vows;

- Ethical audit;

- Human resource management respecting ethical criteria;

- Moral counselling.

Empirical research undertaken conclusion was that ethical training method is 
considered the most important and the means to enforce (signing an oath, performance evaluation, penalties, etc.) are of less importance in getting staff to respect ethical rules, contrary to the common view that taxation and sanctioning mechanisms are most effective (Collins, 2012).

Another author, R. Jeurisson speaks four possible approaches of the idea of ethical management. The first is an approach based on respect of the rules ethical codes. The second one is formulated in terms of moral values: employees are expected to come up with creative new solutions to ethical issues, of course a pre-existing legal framework. A third approach is in terms of dialogue with external beneficiaries (stakeholders) (i.e. customers, suppliers and the community) to optimize the moral relationship with them. And the fourth is social dialogue strategy, favorite author, who can give answers in cases where people come to an understanding with difficulty and ethical issues are very controversial (e.g. debates about nuclear energy, human rights in different cultural contexts, etc.). In this latest version, the organization and its external beneficiaries are together responsible for solving adequate problems, being necessary to find ways of ethical decision fit to train and public, democratically. The four approaches are regarded by the author as complementary, each contributing to the final result with an element that the other lack (Jeurissen, 2005).

An interesting evolutionary perspective is shown to us by Rossouw (2008). They go from the observation made by many experts as "organizations undergo a process of evolution in order to increase the sophistication of their terms of performance management ethics" (Rossouw, 2008). The authors identify five stages of this process, five stages of evolution of management ethics, each representing preferred strategy of an organization to think its ethical life management, since the situation totally ignores this dimension and going back to that in which it is fully integrated into all activities of the organization. We will summarize here this view.

The first is the state of immorality (immoral), the total ignorance of the ethical dimension of life organization. At this stage, organizations usually behave immorally and believe that ethics is not something that concerns them. The organization's culture dominates slogans such as "we live in a world of wolves" (alluding to competition latches, which has no time for moral reasons), "survival of the fittest" (competition is not done with gloves moral) "on boys cheek to find his place" (ethical behaviour is despised), "all that matters is the rating (profit)" etc. It is therefore suggested that what pursue business is business, not ethics. Here's a slogan we hear often repeated as a philosophy of professional life, by Romanian filmmakers private television. But not limited to: commercial companies benefiting from management "local" adopted the same strategy of primitive capitalism. We must recognize that in Romania last century morality issue was totally disjoint life businesses and institutions. All these organizations "immoral" are at a precarious level of integration of ethical values. The purpose of such an organization is to maximize profits by any means. Their strategy of ethical man- 
agement is possibly one Machiavellian, meaning that law does not consider it necessary to ethics management organization. Or utilitarian primitive is one which requires making mechanical decisions that are beneficial to as many people (this would be to maximize the good). For example, in this view, a general increase in wages would be more moral than an increase in their only performance-or the use of unethical means would be justified if it leads to results highly desirable (Bowie \& Werhane, 2004). In these organizations there manifest lack of sensitivity to ethical issues and an explicit refusal to grant them attention ("we do not have educational responsibilities, moral"-repeat convinced our private television station managers). They are immune to ethical expectations of the beneficiaries (public complaints on violence films, poor quality and entertaining programs vulgarity, lewd and morbid taste for cultivation scandal and subhuman etc.) "Using the remote control"- they answer them cynical. "It sells, it speakers". In these organizations there is practically an ethical climate, internal ethical debates, everything is subordinated to profit obsession ("public"). There is no element of ethical management even serious ethical codes designed. Such a rudimentary model has its pseudo-ethical management of its risks. History has shown that, at some point, the financial consequences of immorality can become fatal. For once the public has lost confidence in a service provider, it is virtually impossible to regain it again. Then there might be a rift between amoral culture of the organization and ethical preferences of a part of the staff-which can generate its migration or remain in a state of dissatisfaction smouldering. But this latent dissatisfaction can explode during the first public scandal. Followed by collapse, the risk of scandal in organizations "immoral" is extremely high. Relationships with beneficiaries conned may deteriorate and they gradually to a level that is unresolved, causing the collapse of the organization. Experience shows that systematic ignoring of ethical aspects of an organization can gradually lead to major managerial difficulties, even bankruptcy of the company, as was the case with Enron. But are tiny circulations of newspapers and have root Romanian not here? (The author of this book does not buy Romanian press of the time it felt like it mocked how incompetent and defiant in what's written. One day, only the first page of a newspaper had articles rest were advertisements. In another newspaper allegedly "independent", practiced forms indecent propaganda partisan politics; for example, the editor affords to write: "the democratic Convention is by definition democratic" at that moment, a reader Romanian who buy daily said newspapers no longer buy and it's unlikely that you will ever buy.)

A higher stage of ethical management is reactive. At this stage, managers realize that something must be done to avoid risks of unethical behaviour. For them, these risks are real. But their competence total lack ethics. "Such organizations have convinced naive as a display of moral engagement (present a set of moral values) will create the right context for ethical behaviour. These organizations claim to be ethical without assuring however the conformity of their management to the set established ethical standards." They have adopted formal ethical 
codes but do nothing with them. This is in reality a sample incapable of ethical management and therefore immoral behaviours prevail in these organizations. But such behaviour usually remains unpunished because there is a culture of evil represented by them; it is more convenient and more profitable (in terms selfish) overlook them ("Why do my enemies?"). I find that Romanian universities, and organizations in general in our country that have adopted formal ethical codes, are at this stage of development management. Organizations are at this stage are apparently sensitive to threats from unethical behaviour and shall act for them para standard behaviour, moral codes. However, they are rather formal and remain just a paper in the drawer. There is no attempt to duplicate procedures for applying ethical standards; nor are developed forms of ethical management itself-substituting administration committees of ethics, so some structures remain functional. Here's what actually happened: forced by the authorities, company management control of a person writing a code of ethics without being interested (without knowing) to apply it and develop it. That person who copies, usually from other organizations without consulting members of their organization or its beneficiaries exhibits a non-ethical behavior. Not being trained in implementing the Code, employees are not aware of it or watch it as a foreign body imposed arbitrarily by management. The temptation to defy him is so great. Once adopted, the code of ethics should be developed along with the accumulation of new experiences but, unfortunately, its development is no longer (due to lack of interest and methods), was, at best, a rare event, not a continuous process, professionalized. There are no competent people with ethical company; there are no ethics specialists in methods of decision-the tools that could guide the code change or of solving moral dilemmas of the profession. Ethical management reactive stage rarely progresses beyond the creation of codes of ethics adopted formally; he is actually one of laissez-faire. Required to adopt ethical codes do not know what to do, a lot of organizations in Romania are today in such an uncertain stage of evolution. Reactive organizations usually mine the existence of a gap between words and deeds. This gradually leads to a credibility crisis among the beneficiaries. Lack of security and predictability causes the same lack of confidence (see public attitude towards the quality of Romanian education, despite official slogans exalting the successes and "Olympians"). As organizations at the stage immoral, those in the reactive stage are very sensitive to scandal-easily triggered as long as there is a gap between actual behaviour and ethical standards. Formal gestures do not convince any staff or beneficiaries and lack of trust can thus move up to lethal levels. Since the very existence of codes does not guarantee moral behaviour, which would require the addition would be a more pro-active managerial attitude, a commitment to effective ethics organizations.

Stage accordance ethics satisfy this requirement. Achieving this third stage in the evolution of ethical management means hiring conscious organizations in monitoring and managing their ethical performance. "Instead we have only a 
code of ethics in order to reassure the beneficiaries, the code becomes the standard against which the Company measures its own performance ethics" (Kaptein, 1998). Code is enforced by disciplinary measures and penalties which are tracked by the Administration. Management's aim here is to prevent unethical behaviour and eliminate costs related to it, that those behaviours affect the organization's reputation such as scandals or frauds. We know that a good reputation ethics attract investors, attract and consumers-who are increasingly paying attention to the details of Ethics (for example to correct labelling because they want to be respected) - and keeps talented employees in the organization. Organizations are into conformity ethics explicitly engages in regulating life in eradicating ethical and unethical behaviour. They regularly review their code of ethics to adapt it to circumstances. To be effective, the code must be completed by the existence of managerial functions to direct the process to follow it. This can be ensured by a "work ethic" or "compliance office" (compliance office). Management process can be even more complex and include periodic audits of public reporting ethics and ethical performance of the organization. The downside is that the organization's ethical standards are imposed from outside, which diminishes the moral autonomy and personal responsibility. This type of management bureaucracy is at risk (artificial multiplication of rules and their obsession with imposing penalties). So it is that the ethical codes also find a substantial chapter of administrative sanctions, even criminal, ethical committees and functions are reduced to only one: the resolution of disputes (see Romanian laws regulating this matter). The next step should exceed this heteronomy.

Stage ethical integrity is one that provides just internalized values and ethical standards. Instead to pursue their imposition from outside is aimed subjective hiring staff in relation to a lot of values that are specific to the organization and get to define ("integrity" of the organization). Once it enters in particular-which requires special managerial competence-the "formation of values and employment value" in an organization. Its aim is now not only profit but also raising ethical performance, but not so by penalizing unethical behaviours as encouraging ethical behaviour. Organizations undertake this path when realizing that "performance ethic is strategically important and is a contributing factor in competition." Management strategy specific to this stage is one that "facilitates the internalization of ethical standards in all members of the organization". Such a strategy begins with a comprehensive diagnosis of the ethical culture of the organization; it promotes discussion of the ethical aspects of life as a model organization and believes that it provides moral leaders are decisive. Formation of people able to take informed decisions on ethical (their training "methods of ethical decision") and an emphasis on rewards, not penalties, are also characteristics of organizations are at this stage of evolution. Internalization of values has the effect that employees have the responsibility and ability to make ethical management at each place of work. Over time, the place has such a profound transformation in organizational culture-a sign of what the authors call a "transformational management." 
Finally, total alignment stage is characterized by an integration of ethics in order, the particular mission and goals of the organization. "Ethics is not regarded as one of the aspects to be and he led organization, but as an integral part of the organization without which it cannot fulfil its purpose and mission." Ethical behaviour is seen as having strategic importance and unethical behaviour is seen not only as a threat to business success, but as the undermining even its reason for being. The aim is to strengthen ethical management as an essential part of the culture morality and purpose of the organization. For example, at this stage ethics is recognized as an essential part of the business world. The organization will of course create a management function specific (a director with ethical issues) and an ethics committee, but its specificity consists in that all managers of the organization must play a role in this process, that must integrate ethics into their own structure management. Managerial Responsibility Ethics is no longer limited to special ethics function, but is dispersed throughout the organization and at all levels of managerial. Communication is an important management tool both internally and in relation to external recipients to which organization is responsible. Such an organization will not focus on punishing unethical behaviour nor reward ethical, but the celebration of the organization's heroes, those personalities in the field who embodies the vision, purpose and moral commitments of the organization. Hiring ethics becomes a second nature of its members.

This description of the five stages of evolution ethical management by Rossouw and can be a useful heuristic tool in the effort of awareness of the differences between the various organizations and ethical management in an attempt to sketch a direction in its evolution. In this way we can more easily locate and can suspect what awaits us. Table 1 presents a summary made by the two authors.

\subsection{Ethical Organization}

A "moral organization" is one that respects at least the following four principles:

1) Interact with beneficiaries varied natural and basic rules they make good beneficiaries good part of their organization; 2) The members are extremely sensitive to impartiality theme: their basic rules stipulate that the interests of others matter as much as their own interests; deceit and exploitation of clients is their nightmare; 3) Responsibility is seen as individual rather than collective; you cannot hide behind the organization; members must be individuals who assume personal responsibility for the actions of the organization; its rules establish that individuals are responsible for themselves; 4) They shall concern in terms of objectives; target is an operating mode that is highly valued by the organization and its members binds to the external environment (Henn, 2009). Obviously, all these things are related to an advanced stage of evolution of ethics management in organizations (Boylan, 2013), the user or ethical management believes that a mature distribution of roles and responsibilities in an organization that takes seriously the ethical management also would require institutional changes: 
Table 1. Ethical management stages.

\begin{tabular}{|c|c|c|c|c|c|}
\hline & Immoral stage & Reactive stage & Conformity stage & Integrity stage & Total alignment stage \\
\hline $\begin{array}{l}\text { The nature } \\
\text { of these } \\
\text { phases }\end{array}$ & $\begin{array}{l}\text { Unethical conduct is } \\
\text { good business. } \\
\text { The purpose of business } \\
\text { is business, not ethics. }\end{array}$ & $\begin{array}{l}\text { Gestures forms of } \\
\text { ethical sensitivity to } \\
\text { (adopt codes of ethics). } \\
\text { Unethical behaviour is } \\
\text { innocent and often } \\
\text { covered. }\end{array}$ & $\begin{array}{l}\text { A direct engagement in } \\
\text { ethical performance } \\
\text { monitoring and } \\
\text { management. } \\
\text { An approach from the } \\
\text { perspective of ethics } \\
\text { rules. } \\
\text { Disciplining unethical } \\
\text { behaviour through } \\
\text { punishment. }\end{array}$ & $\begin{array}{l}\text { Internalization of values } \\
\text { and ethical standards. } \\
\text { One approach ethics } \\
\text { from the perspective of } \\
\text { internal values, not } \\
\text { external rules. } \\
\text { Internal ethical review; } \\
\text { ethical debates. }\end{array}$ & $\begin{array}{l}\text { Integrating ethics in } \\
\text { order, strategy and } \\
\text { business operations. } \\
\text { Interaction responsible, } \\
\text { moral, non-negotiable } \\
\text { beneficiaries. }\end{array}$ \\
\hline $\begin{array}{l}\text { The main } \\
\text { goal } \\
\text { pursued }\end{array}$ & $\begin{array}{l}\text { Ethics has no place in } \\
\text { the organization's } \\
\text { activities. } \\
\text { Unethical behaviour is } \\
\text { presented as a good deal. }\end{array}$ & $\begin{array}{l}\text { Protection organization } \\
\text { in counteracting the } \\
\text { dangers of unethical } \\
\text { behaviour. } \\
\text { Sceptics and critics are } \\
\text { silenced by the existence } \\
\text { of ethical standards. }\end{array}$ & $\begin{array}{l}\text { Preventing unethical } \\
\text { behaviour. } \\
\text { The desire to have a } \\
\text { good reputation ethics. }\end{array}$ & $\begin{array}{l}\text { Raising ethical } \\
\text { performance of the } \\
\text { organization. } \\
\text { Proactively promote } \\
\text { ethical behaviour. } \\
\text { Ethics is strategically } \\
\text { important. }\end{array}$ & $\begin{array}{l}\text { Ethics is part of the } \\
\text { culture and purpose of } \\
\text { the organization. } \\
\text { Ethics is implied in the } \\
\text { speech and in the } \\
\text { decision. }\end{array}$ \\
\hline $\begin{array}{l}\text { Ethical } \\
\text { management } \\
\text { strategy }\end{array}$ & $\begin{array}{l}\text { A Machiavellian theory. } \\
\text { The main goal pursued } \\
\text { negates the need for } \\
\text { ethical decision. } \\
\text { No concern for } \\
\text { beneficiaries. } \\
\text { No ethical management } \\
\text { strategy. }\end{array}$ & $\begin{array}{l}\text { Ethical management of } \\
\text { laissez-faire. } \\
\text { Inability to genuine } \\
\text { ethical management. } \\
\text { Ethical values of the } \\
\text { organization are just } \\
\text { words on paper. }\end{array}$ & $\begin{array}{l}\text { Ethical management of } \\
\text { transactional type } \\
\text { (unethical behaviour is a } \\
\text { cost to be reduced). } \\
\text { Clear and } \\
\text { comprehensive ethical } \\
\text { code. } \\
\text { Ethical management } \\
\text { systems are used. } \\
\text { Unethical behaviour is } \\
\text { punished. }\end{array}$ & $\begin{array}{l}\text { Transformational ethical } \\
\text { management type. } \\
\text { Involving beneficiaries. } \\
\text { Prevail "discussions" } \\
\text { ethical. } \\
\text { Systems management } \\
\text { functions and high } \\
\text { ethical. } \\
\text { Managers have } \\
\text { competence ethics. }\end{array}$ & $\begin{array}{l}\text { All are responsible for } \\
\text { ethical management. } \\
\text { Function ethics/ethics } \\
\text { office acts as a "rudder". } \\
\text { Celebrate heroes are } \\
\text { ethical and moral stories } \\
\text { are recounted. } \\
\text { Eliminating discrepancies } \\
\text { between moral values } \\
\text { and behaviour. }\end{array}$ \\
\hline $\begin{array}{l}\text { Challenges } \\
\text { and future } \\
\text { risks }\end{array}$ & $\begin{array}{l}\text { The financial } \\
\text { consequences of } \\
\text { immorality are } \\
\text { becoming unbearable. } \\
\text { The discrepancy } \\
\text { between increasing } \\
\text { personal and } \\
\text { organizational values. } \\
\text { Customers have a sense }\end{array}$ & $\begin{array}{l}\text { Sensitivity to ethical } \\
\text { scandal. } \\
\text { Low ethical reputation } \\
\text { of the organization. } \\
\text { Issues of credibility with } \\
\text { customers. }\end{array}$ & $\begin{array}{l}\text { The mentality of "what } \\
\text { is not forbidden is } \\
\text { allowed." } \\
\text { Suffocation by rules } \\
\text { imposed from outside } \\
\text { autonomy and personal } \\
\text { responsibility. } \\
\text { The proliferation of } \\
\text { ethical rules. }\end{array}$ & $\begin{array}{l}\text { Moral autonomy leads } \\
\text { to moral dissent. } \\
\text { Strong leaders } \\
\text { undermine ethical } \\
\text { mechanism. } \\
\text { Lack of identity that } \\
\text { affects ethical integrity } \\
\text { phase. }\end{array}$ & $\begin{array}{l}\text { Self-sufficiency/ } \\
\text { Arrogance ethics. } \\
\text { Moral laxity. } \\
\text { Neglect of ethical } \\
\text { training of new } \\
\text { employees. } \\
\text { Lack of coordination in } \\
\text { ethical management. }\end{array}$ \\
\hline
\end{tabular}

1) The Executive Director of the organization to effectively support ethical programs; if he does not believe in them, they are unlikely to succeed;

2) It must be an ethics committee at the central governing bodies, whose role is to oversee the ethical management program;

3) It also constituted a committee for ethical management, designed to implement and manage "ethics programs", including policies and procedures with poignant moral character and resolve dilemmas and moral conflicts that may stifle the atmosphere in an organization; 
4) It should be established as director with ethical issues, a person who combines knowledge and managerial experience to that of practical ethics; it's important to remember that one person should be ultimately responsible for the ethical management of the organization-which becomes the object of a new profession;

5) It is good to establish the function of "Ombudsman"- a person responsible for the institutionalization of moral values in the workplace, and solving moral dilemmas wise interpretation of policies and procedures and through close contact with staff and beneficiaries.

Unfortunately, there are few organizations today that are serious ethical programs. These programs would indeed be quite complicated, awkward loads and also comprising usually perceived as redundant (Vasilache, 2010):

1) Creation and development of ethical codes-which articulates the organization's expectations farms on morality;

2) Organizing and chairing committees of ethics designed to handle an ethical policy development, evaluation and organization actions and decisions of employees, research and punishing cases of deviation from the rules;

3) Development of ethics communication systems (e.g. telephone lines) as a means available to employees to report abuses or to ask for advice;

4) Existence of a director with ethical issues or "Ombudsperson" to coordinate ethics education policies, to investigate rumours and settle conflicts;

5) Ethical training organization, such as those aimed at training professional virtues;

6) Performance of activities of unethical conduct disciplinary case;

7) Creation of an institutional culture of respect for the specific values of the organization.

In short, I would say that the main "instruments" of the person in charge of management ethics are:

- Ethical committees

- Codes of ethics

- Ethics instruction (training ethic)

- Ethical audit

- Methods of ethical decision

\subsection{Typology of Ethical Review Processes}

We might ask ourselves now are ethical competence of a person involved in such activities. Some are professional skills in the ethics of moral philosophy in the academic world and others specific to a member of the ethics committee. To not confuse things and because there is no universally accepted terminology, we think it is useful to distinguish between:

- Analyses of ethical practice

- Ethical assessments (audits ethical)

- Ethical decision 
The first category refers to the kind of philosophical analysis of traditional academic in the field of applied ethics, as it appears in most textbooks Profile overall. The second aim of the ethics audit firms or other organizations through the application of evaluation matrix (ethical assessment). And the third has to do with processes highest professionalized resolution of ethical issues unique in that there is a political interest major, such as the acceptability moral of new biotechnologies, new medical techniques or resolving moral dilemmas that can arise the writing process and developing codes of ethics (ethical Decision Making). We think only the last two are part of the baggage of a competent director with ethical issues (along with many others).

Analyses of ethics practice the kind of evaluative discussion, qualitative, in cases of hot public agenda (abortion, homosexuality, rights, environment, euthanasia, artificial insemination, etc.) using the resources broad conceptual philosophy in general and of moral philosophy in particular, especially certain ethical theories without requires a special scientific training and discussion and clarification aimed at an elevated level and methodological tools, these general themes. It's an approach that exploits fully applied ethics guide qualities of ethical theories and other chapters of moral philosophy, proposing a repertoire of moral judgment to the facts that is broadly accessible to all. In this approach:

Applied ethics is an application of moral philosophy, particularly ethical theories, the hot cases on the public agenda, which does not require special scientific expertise.

In this way discuss, for example, Flonta (2002) responsibility of the intellectual elite in totalitarian regimes (Nazi and Communist), without using an explicit moral judgment and technical framework, but ethical principles implicit and subtle argumentation based on a solid philosophical training. The same is the type of items collected in different classic applied ethics manual (Newton, 2006).

In general, this approach requires two conditions:

1) Rational argument to show that it is possible to morality (as long as others deny this); this requires recourse to meta-ethical theories proving that moral discourse is a rational discourse.

2) To have the reach and utilize-explicit or tacit-methods of moral decision; this involves appealing to normative ethical theories or methods that are not based on theory, but not totally reject them (like moral casuistry).

The first issue, we see that followers bias meta-ethical (a phrase moral describes the mental state approval of the speaker) or those of emotivism (sentence morality express attitudes or feelings) negates the possibility dispute logical ethics and so the character argument of speech moral. After these authors, the ethics debate, but apparently rational, would take more than rhetoric or propaganda and psychological persuasion, not by rational argument. But also no meta-ethics issues are of interest to ethical manager of an organization.

On the question 2), applied ethics textbooks (and student essays) indicates 
several possible manners of approach that have been practiced so far:

1) Analysis of a case of ethical practice (e.g. capital punishment) consists in transferring the case that many ethical theories (utilitarian, deontology, natural law, Christian virtue ethics etc.) recording the results related to the moral acceptability of the case after each evaluation. It appeals to a factual material as rich and gets a list of solutions, without concluding in some way, for example by synthesizing them. The final solution remains an open question (suggesting that ethics there is never one solution), even when theories (principles) different ethical lead to opposite results. Such a response "open" cannot, however, do not displease. People will rather firm conclusions about their moral problems, not confirming impossibility of such conclusions. This process of moral judgment seems rather of functioning one test of a theory than an actual evaluation of a moral case (Hartley, 1993).

2) Analysis of ethical practice consists of a case through several ethical theories and extracting a final answer by comparing and weighing all mutual alternative outcomes, using our moral discernment that we have each other. The debate now has the appearance of a discussion and choices between alternatives, each with its arguments pro and con, indicating the reasons we went to the final option. Such a final decision is not based on rules, but the Aristotelian "practical wisdom" (Miroiu, 1995).

3) Analysis of ethics and practice may be indicating a battery of tests-logical and ethical-that need to pass a moral solution to be acceptable. We can use, depending on the topic discussed, as are the established principles of the sacredness of life, the negative utilitarianism, Christian ethics, utilitarianism of classic theories of rights etc. We arguments and counterarguments, following disagreements factual concepts unclear or inconsistent, inconsistencies in principles somebody, highlighting the consequences of unacceptable person ignored them, use cases imagined for choosing between explanations moral alternative, aiming ultimately to "harmonize theories and observations". No battery of tests, however, does not provide a unique and definitive agreement verdict of those who are in dispute morality. One such method-based on several principles, ethical and non-ethical-J. Glover uses in his practice ethics Causing Death and Saving Lives (Muresan, 2006).

4) Analysis of ethical practice can be done by adopting, on the basis of arguments, some theory and ethics on specific cases only through them. So make when P. Singer adopt a utilitarian method suggested by RM Hare, without ignoring total other approaches (rights theory, theory of justice, sacredness of life theory etc.), and leaving the reader to make himself an opinion on comparative merits of utilitarian and non-utilitarian approaches (Muresan, 2006).

5) Analysis of ethical practice can be done using a method that does not rely on own theory, but does not deny the usefulness of theoretical instruction, namely the method of cases or moral casuistry. It is a method based on fixing the instructor of a repertoire of paradigmatic cases to discuss a class of problems, 
following those new situations is cut by analogy with paradigmatic cases (Donaldson \& Gini, 1990).

Analyses of ethical practice specific to academia, especially the philosophical, is an extension of applied studies of theoretical moral philosophy. They imply an ethical-philosophical training and a solid knowledge of the facts broadly, the evaluation is usually a global, intuitive indicative. We think they can provide a long life in this environment, as in that of basic education if requirements are adapted to age.

Ethical audit is a new field of activity, at least not for students. It consists in examining the status of an ethical organization to see if changes are needed in its ethical policies. Organizations can be companies, especially transnational ones (facing conflict characteristic values of different cultures), ethics committees, public administration institutions, and various scientific research programs or projects that require financing social actions in a competitive context etc. In the US, companies have employed lately a director in charge of promoting ethical behaviour in the company. In Europe, this function is rare, but most businesses have created codes of ethics.

Ethical audit is the process by which we measure the "ethical climate", i.e. internal and external coherence basic moral values of an organization. He seeks to determine what values and moral standards are in operation if they are tracked or not, if targets are met ethical organization (internal control) and, on the other hand, if the organization behave responsibly and transparently with partners, taking into account, when applicable, cultural differences, values that can occur especially in situations where partners are located in different countries (external side) (Serban et al., 2008). The audit establishes ethical moral profile of an organization, the factors that affect the reputation and the image that has eyes partners and the public consumer.

Questions of a grid of audit vary from case to case. Generally, they ask for information about who is responsible for ethical implications of the Organization's activities, about the status of Ethics Committees of the partners require ethical opinion about who handles the application and development of the code of ethics, about the extent to which partners are satisfied with the procedures faced ethical review their activities, about the extent to which organization members feel that there truly ethical in their work etc. If transnational companies became complex: there are new related corruption (in the context of different cultures), different work habits, respect for human rights etc. (Lefter et al., 2010).

Ethical audit will become a tool for highlighting the extent to which, beyond words, ethical management is actually part of the leadership of an organization agenda. Directors usually like to present in public the "high standards of moral integrity" and then fail to run the company. Ask what this means, no longer serve a certain response and the emotional rhetoric cannot be understood too much. How can we move beyond this misleading verbiage in delighting everyone? Among others applying ethical standards audit internally and externally. 
The activities of judging morality that uses methods of decision ethic are characteristic political and professional organizations that are morality responsible for their decisions realize in front of the public for the consequences of choices made and consider why they need methods that give their decision support argumentative highest level and, therefore, credibility. It's the political institutions of national or European level, professional organizations, the National Ethics Council, groups of evaluation employed by various political institutions to trance uncertainties or moral dilemmas with great social impact and financial (e.g. acceptability morality of cloning beings human commercialization of genetically engineered food, etc.). They seem to assume the participation of specialists in applied ethics (i.e. medical ethics, bioethics, business ethics, ethics of biotechnology, etc.), but also the general public. The final opinion, even if temporary, is one based on a consideration as careful and thorough as possible the facts using other methods complementary risk assessment, analysis of the parties involved, the calculation of cost-benefit, Delphi, conferences regarding consensus etc. Factual consequences of an action or decision are no longer around and lacunar determine, based on intuition, but as systematically and accurately as possible based on scientific research and critical debate of specialists.

The most common method of this kind is the various forms of "principles", although new cases judging by subordination to universal principles was accused of "implicit paternalism," i.e., non-recognition of diversity and pluralism ethical values that define modern democracy. So-called "ethical matrix", derived from principles, seeks, inter alia, to respond to this criticism and recover the idea of ethical pluralism. Caught between the need to be as scientific (using so inevitably experts), namely to listen to the democratic voice of the people, the common man, who is dealing with this issue have found non-existent so far a satisfactory response to this challenge. The solution appeared for some to be the institutionalization of ethics, establishment of "ethics committees", which happened throughout Europe. The difficulty that remained, however, is that there is no consensus on what it means-under a methodological aspect-that an ethics committee who competently treats a moral issue. Therefore there is today a growing interest in developing "toolbox ethical" (ethical toolbox) making it possible to issue a "notice of ethics" well argued, supports transparent and democratic pluralism axiological of our societies (see the "ethical tools" of the European Commission). They contain not only "teaching-support rating morals" such as those listed below, but also more traditional such as public debates, citizens' jury, conferences regarding consensus, public meetings of ethical decision matrix based on ethics etc.

We will present here some methods of ethical decision, more specific institutionalized than the academic ethics:

- Bi-levelling utilitarian method of R. M. Hare

- Principles theory

- Matrix of ethics 
- Christian ethics

- Moral casuistry

- Other methods of ethical decision

Learning and practicing them does not ensure a miraculous tool of obtaining definitive answers, but rather we provide a methodological framework apt to order our thinking and ethics give us a full systematic case, the map able to help us reach an ethical decision-a decision that is, however, always revisable (Giles, 2015). Methods of decision ethic above - to which we add the methodology of building codes and ethical committees-can help to train thinking moral systematic staff of an organization to support rational acceptability/unacceptability moral of new technologies or commercialization of new food, to justify making political decisions or adopting major public policy, the development of ethical codes and solving moral dilemmas that exceed the powers of ordinary ethical discernment (McInnery \& Rainbolt, 1994). Everyone is free to choose the method which seems to fit best case analysis. However, we present here a pluralist procedure that uses all these methods simultaneously (Trevino \& Weaver, 2003).

\section{Corruption in EU}

At the beginning of 2018 two new Eurobarometer surveys were conducted to develop the EU Anti-Corruption Report, as compared to 2014: 1) a special Eurobarometer survey ${ }^{1}$ and 2) a survey "Flash" focused on enterprises (see footnotes for explanations of the survey methodology, in the case of the two surveys). For most countries, the ranking obtained using the corruption perception index (CPI) published by Transparency International in August tends to match the responses of respondents to the Eurobarometer surveys ${ }^{3}$.

Given the data in the Eurobarometer survey specifically regarding, first, the general perception regarding the prevalence of corruption and, secondly, the concrete situations in which respondents were asked to give bribe (personal experience on corruption) it is clear that Member States can be characterized in different ways (see Figure 1, for Romania):

\footnotetext{
${ }^{1}$ The survey conducted among the population in all Member States once every two years based on direct interviews of a sample 1000 or 500 respondents (depending on the size of the population). A total of 27,786 people (Representative sample) participated in this survey, in the interval between late February and early March 2018. Among the issues addressed in the survey include the perception that citizens have Europeans on corruption in general, their personal experience in this area and their attitude favors and gifts. Although since 2007 Eurobarometer surveys are held every two years, in 2013 the Commission first decided to adapt the questions to the needs of this report. Therefore, any comparison with surveys in previous years it should be undertaken with caution. The full report is available at: http://ec.europa.eu/public opinion/archives/eb special 399380 en.htm\#397.

${ }^{2} \mathrm{~A}$ telephone survey, the so-called Flash Eurobarometer survey, covering six areas in UE28, was launched first time in 2013, and repeated in 2018, during the period February 18 to March 8. Businesses (of all sizes) of energy, health, construction, manufacturing, telecommunications and finance were invited to rule In this regard. The full report is available at: http://ec.europa.eu/public opinion/archives/flash arch 374361 en.htm\#374.

${ }^{3}$ Corruption Perceptions Index (CPI) is published annually by Transparency International: http://cpi.transparency.org/cpi2013/.
} 


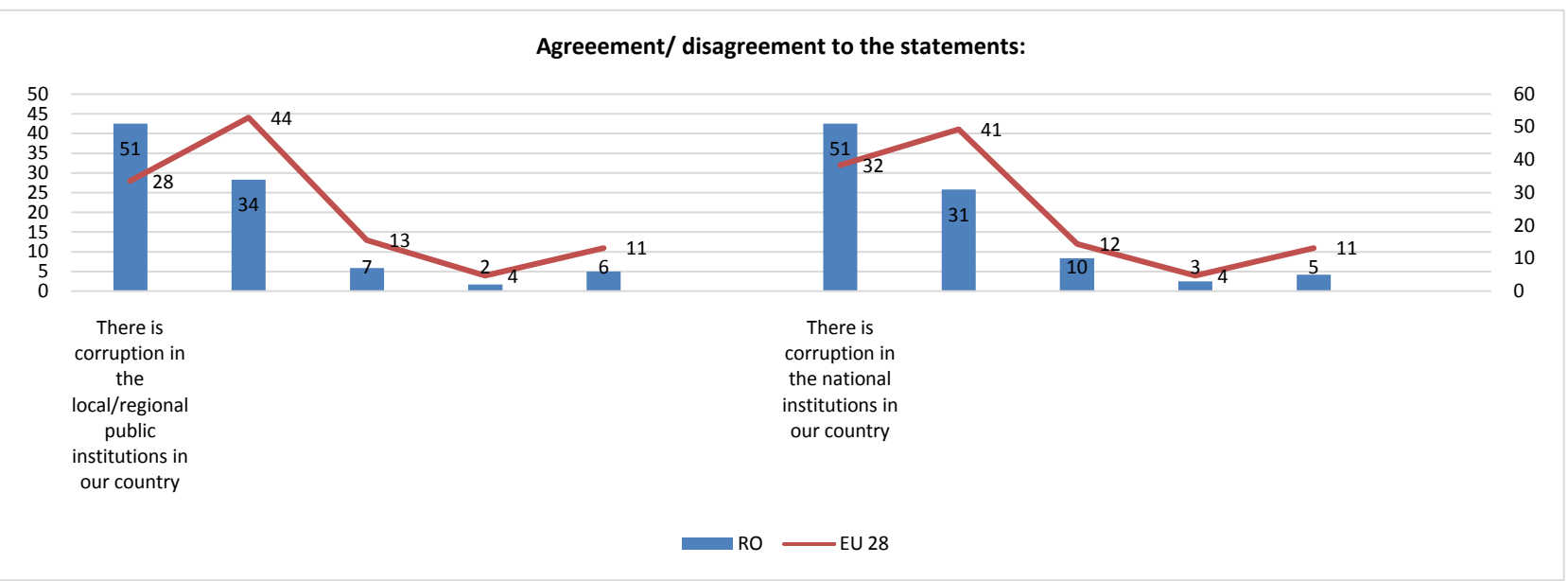

Figure 1. Perception of corruption in Romania.

Responses confirmed a positive perception of the phenomenon and the limited experience of giving or taking bribes to Denmark, Finland, Luxembourg and Sweden. Respondents in these countries indicated that they were asked rarely bribe (less than $1 \%$ of cases) and the number of people who believe that corruption is widespread $(20 \%, 29 \%, 42 \%$ and, $44 \%)$ is well below the EU average. In the UK, only 5 people in 1115 were faced with a situation in which they were asked to pay bribes (less than 1\%), which is the best result recorded across Europe; However, according to data on perception, $64 \%$ of British respondents believe that corruption is widespread in their country (the EU average is $74 \%$ ).

In countries like Germany, the Netherlands, Belgium, Estonia and France, even though more than half of respondents believe that corruption is widespread, the actual number of people who were forced to give bribes is low (about $2 \%)$. These countries also appear among those who have had good results in the ranking of Transparency International index. Austria has characteristics similar to other countries in this group, except that a relatively large number of respondents (5\%) reported that they were being asked to pay bribes.

In some countries, including Hungary (13\%), Slovakia (14\%) and Poland (15\%), a relatively large number of people indicated that they had to make personnel corruption, this experience but was concentrated clearly on a limited number of sectors. In these countries, most cases of corruption involved in a single sector, namely that of health. There is evidence that structural problems affecting the health sector are an incitement to bribery with regard to medical personnel. Indeed, in all the countries mentioned above, detailed answer demonstrates that health is cited by the largest number of people, while all other institutions or sectors (e.g., police, customs, politicians, the prosecution etc.) were mentioned by less than $1 \%$ of respondents.

In a more general sense, corruption is perceived as widespread in these countries (82\% in Poland, $89 \%$ in Hungary and $90 \%$ in Slovakia). In some countries, including Portugal, Slovenia, Spain and Italy, bribery seems to be a rare phe- 
nomenon, but corruption in the broad sense is a serious cause for concern: a relatively small number (4\%) of respondents said they were requested in explicit or implicit bribe in the past 12 months. Even if personal experiences on corruption are rare $(1 \%-3 \%)$, the perception of this phenomenon is so heavily influenced by recent political scandals and the financial and economic crisis that this translates into a negative impression that respondents with regard to corruption have, in general (90\%, 91\%, 95\% and, respectively, 97\%).

Countries were ranked last in terms of both perception and actual experience on corruption, are Croatia, the Czech Republic, Lithuania, Bulgaria, Romania and Greece. In these countries, between $6 \%$ and $29 \%$ of respondents indicated that they were asked or suggested to bribe in the past 12 months, while between $84 \%$ and $99 \%$ of respondents believe that corruption is widespread in their country. Croatia and the Czech Republic seem to leave a somewhat more positive impression to perform relatively better than other countries in the same group. Countries which have not been mentioned (i.e., Latvia, Malta, Ireland and Cyprus) presented results that differ substantially from the EU average in any of the issues raised.

At European level, three quarters of respondents (76\%) believe that corruption is widespread in their country. Greece (99\%), Italy (97\%), Lithuania, Spain and the Czech Republic (95\% each one) are the countries where respondents are inclined to believe that corruption is widespread. A quarter of Europeans (26\%), compared to $29 \%$ according to the Eurobarometer survey in 2011, believes that personally affected by corruption in their daily lives. Citizens in Spain and Greece (63\% in each of the two countries), Cyprus and Romania (57\% in each of the two countries) and Croatia (55\%) are inclined to say that personally affected by corruption; while in Denmark (3\%), France and Germany (6\% in each of the two countries) is highly unlikely that citizens affirm this. Approximately one European in twelve (8\%) say they were confronted with a case of corruption or that has witnessed such an event in the last 12 months. Respondents in Lithuania (25\%), Slovakia (21\%) and Poland (16\%) are inclined to say that faced with a case of corruption or that have witnessed such an event while in Finland and Denmark (3\% in each of the two countries), Malta and the United Kingdom ( $4 \%$ in each of the two countries) is highly unlikely that respondents affirm this.

About three quarters of Europeans (73\%) say that resorting to bribery and personal relationships are often the simplest way to obtain certain public services in their country in August. This belief is most widespread in Greece (93\%), Cyprus (92\%), Slovakia and Croatia (89\% in each one). Just like in 2011, about two Europeans in three $(67 \%)$ consider that funding political parties are not sufficiently transparent and monitored. Respondents in Spain (87\%), Greece (86\%) and Czech Republic (81\%) lean most to share this view, while in Denmark (47\%), the UK (54\%), Sweden ( 55\%) and Finland (56\%) are highly unlikely that respondents to this opinion. 
Almost a quarter of Europeans (23\%) agree that their governments efforts to combat corruption are constructive; about a quarter of Europeans (26\%) believes that a sufficient number of prosecutions have been concluded successfully in their country so as to discourage their compatriots from practicing corruption. The survey Flash focused on enterprises, the results for each country vary impressively: there is a difference of 89 percentage points between the highest (Greece: 99\%) and the lowest (Denmark: 10\%) as the perception of corruption. (Observe the same result in the survey "Eurobarometer" shown above: $20 \%$ to 99\%.) Indeed, all respondents in Greece, with the exception of one person, are convinced that corruption is widespread in this country.

At European level, more than 4 in 10 companies believe that both corruption and clientelism and nepotism in business raises. When asked if corruption raises clear issues in business, $50 \%$ of businesses in the construction sector and $33 \%$ of the telecommunications/information technologies have replied that this is a serious problem. The society is less, the more corruption and nepotism appear to raise issues in business. Companies in the Czech Republic (71\%), Portugal (68\%), Greece and Slovakia (by $66 \%$ each) were the most tend to consider that corruption is a problem in business.

\section{Corruption in Public and Private Organizations}

\subsection{The Sample Size}

A questionnaire for determining corruption in public and private organizations was developed in order to conduct a study on the causes and extent of spread of corruption in Romanian society, as well as for efficient cooperation with civil society.

Recruiting subject which will form the sample under investigation is one of the most important steps in the implementation of an interview plus pencil and paper is based on a short questionnaire comprising: identifying questions of respondents; questions related forms of corruption; if you are willing to answer a number of questions; date, time and place-most convenient to conduct the interview.

On the basis of our decision to choose the 53 persons, which formed an accessibility sample, are characteristic forms of corruption that are found in Romanian society. Of these 53 persons, 27 represent public institutions and 26 private companies. We didn't find it appropriate to survey the general population, because of exposure to the phenomenon and, accordingly, perceptions may vary, and we already had the database of the Eurobarometer as a term of comparison.

Examples of questions that recruiting subjects had to fill in the survey can be found below, along with results interpretation. Tables 2-4 summarize Romanians' perception of corruption, at public and private level, from the extension of the phenomenon in society to its trends.

1) For how many years you consider corruption as a dangerous phenomenon for society? 
Table 2. Identification of corruption as a dangerous phenomenon.

\begin{tabular}{ccc}
\hline & Public institutions & Private companies \\
\hline The last year & 2 & 3 \\
5 years ago & 12 & 12 \\
10 years ago & 13 & 11 \\
\hline
\end{tabular}

Source: own research.

Table 3. Level of corruption.

\begin{tabular}{lcccccc}
\hline & Very high & High & Medium & Low & Absent $\begin{array}{c}\text { Don't know/ } \\
\text { No answer }\end{array}$ \\
\hline Public institutions & 10 & 10 & 5 & 1 & - & 1 \\
Private institutions & 1 & 7 & 8 & 8 & 2 & - \\
\hline
\end{tabular}

Source: own research.

Table 4. Trends in corruption in Romania.

\begin{tabular}{lcccc}
\hline & Increased & Decreased & Same level & Not know/ Do not answer \\
\hline Public institutions & 6 & 12 & 7 & 2 \\
Private institutions & 7 & 11 & 4 & 4 \\
\hline
\end{tabular}

Source: own research.

Indicate only one answer.
a) in the last year
b) 5 years ago
c) 10 years ago

Figure 2 indicates that most of the respondents have seen corruption as a dangerous social phenomenon 10 years ago, and the numbers are slightly higher for public institutions, but comparable with the private sector.

2) In your opinion, the level of corruption in Romanian society is:

In Figure 3, there is, obviously, a prevalence in the perceived corruption level in public institutions; most of the respondents declaring it are high or very high.

3) Compared to previous years, in the last year, the level of corruption in Romanian society:

In Figure 4, we may see that respondents assign a slightly decreasing trend to corruption in both public and private organizațional, which indicates their trust in positive reforms and evolution.

\subsection{Analysis and Interpretation of Data}

Our study on corruption approached from the perspective of its own, complete results of scientific studies conducted to date, enhancing the relevance of studies of perception about corruption and ethics in public administration and private companies. The issue of corruption has been addressed in this project, and therefore, in this study, based on rules and through the principles of ethics and 
integrity, all implemented by the public official and employee of private companies whose business is conducted in an environment where transparency and communication should be a primary and essential element in providing services to citizens.

口Public companies $\quad$ Private companies

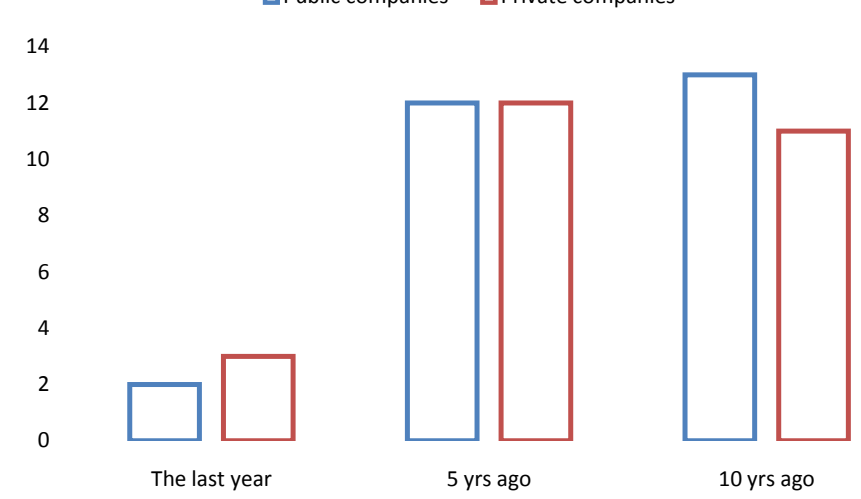

Figure 2. Perception of corruption in society. Source: own research.

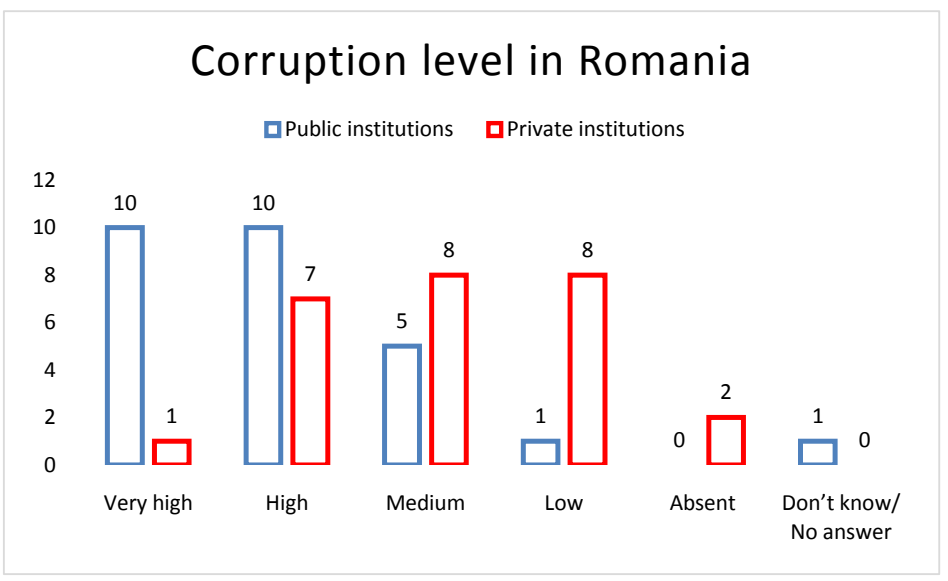

Figure 3. Corruption level in Romania. Source: own research.

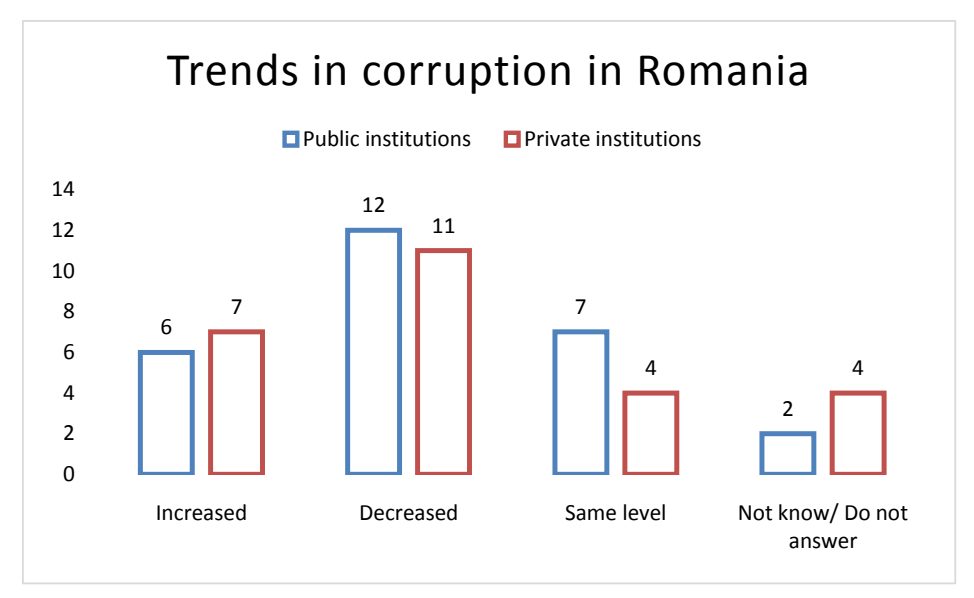

Figure 4. Trends in corruption in Romania. Source: own research. 
It is necessary in this context, an approach cohesive corruption, both at the individual level, the official and employee in the position to choose about the possibility (opportunity) to request or take bribes, and at the macro level, the legislative and structural context that allows or restricts such practices and sanctions system more or less regulated.

Into practice, the issue of ethics and integrity of public official and employee in the private sector under the sign system of checks and penalties, both at micro level of individual and macro, the institution and the system in general. Where both macro-level systems are not well regulated and implemented, remains the system of personal values that allow the employee evaluation of a situation or a problem.

Corruption costs are undoubtedly higher, both economically and in terms of social environment. This should not, however, lead us to stick to economic or political models for tackling corruption. They have integrated a broader approach, which, on the one hand, to permit the disclosure of such practices on a larger scale and with more accuracy and, on the other, to consider and contribute to the development of ways socially recognized moral values, such as honesty, be integrated professional act.

The results of this study suggest, first of all, that the interaction between public and private stakeholders system is still limited to one vendor relationship-passive recipient of services. Therefore, future projects to combat corruption must focus on the change of the nature of this relationship and increase communication between these stakeholders.

The main limitations of the study refer to the availability of secondary data-namely, the release of more recent Eurobarometers, and to the need of conducting large scale surveys, in the Romanian society, taking a stratified sample approach, to deeply analyse the extension of the corruption phenomenon, considering all layers of society which are affected by it.

\section{Conclusion and Recommendation}

\subsection{Recommendation for Public Sector}

\subsubsection{Priority for Anticorruption Policies}

Anticorruption policies have become more visible on the political agenda in Romania. The financial crisis has drawn attention to issues of integrity and accountability of decision makers. Romania, faced with major economic difficulties recognized the seriousness of corruption issues and have already developed (or are developing now) anticorruption programs designed to address the risks inherent in this phenomenon, as well as those related to embezzlement of public funds. However, the long absence of comprehensive anti-corruption strategy in our country has proved to be a concern, since the nature of the problems to be addressed requires a coordinated, comprehensive and centralized.

In Romania it has established a legal and institutional framework complex and sophisticated, and numerous strategies or specific programs. These steps, taken 
separately, but do not necessarily produce concrete results.

\subsubsection{Liability of Elected Officials for Corruption}

One of the key challenges facing anti-corruption policies is the absence, in Romania, of a harmonized definition of "public servant", which would include the elected officials. The proposal for a Directive on the protection provided by criminal law against fraud and other crimes affecting the financial interests of the country, the definition of "public official" includes people who have a legislative mandate. To reach a unified approach at national level needs clear harmonization of criminal liability of elected officials for corruption offenses.

\subsubsection{Internal and External Control Mechanisms}

In public bodies, control mechanisms play an important role in both the prevention and detection of corruption cases. In Romania's case, place a considerable burden on the bodies responsible for enforcement and prosecuting authorities or corruption agencies which are considered solely responsible for the fight against corruption in the country. Even if these institutions are particularly important, deeply rooted corruption cannot be eradicated without a comprehensive approach aimed at strengthening measures to prevent this phenomenon and control mechanisms throughout the public administration at central and local level. It is necessary that these controls be strengthened and correlated with firm policies on prevention to achieve tangible results and sustainable corruption.

\subsubsection{Declaration of Assets}

Declaration of assets by officials occupying sensitive positions is a practice that contributes to strengthening the accountability of civil servants, ensures greater transparency and facilitates the detection of possible cases of illicit enrichment, conflicts of interest, incompatibility, and detection and investigation of potential practices of corruption. As regards the declaration of assets by elected officials, there are different approaches, from the obligation to make public a considerable amount of information limited to the obligation of declaring or even concealing assets. For civil servants employed in certain sectors, asset disclosure could be a solution to avoid conflicts of interest. Despite these different approaches, one can observe a general trend towards more stringent requirements in terms of declaration of assets in respect of civil servants. Verification of these statements is an important aspect. There are few examples of thorough verification that controls are performed substantially by corruption agency/integrity independent, who have the skills and tools necessary to verify the origin of assets of public officials concerned with a wide range of databases (tax, trade register, etc.) to identify any incorrect statements.

\subsubsection{Rules on Conflicts of Interest}

Conflicts of interest reflect a situation in which public officials act or intend to act or give the impression that he is acting for personal gain. Therefore, the issue of conflict of interest is part of the scope of vast panoply of anti-corruption in- 
struments and review mechanisms, including those under the United Nations Convention against Corruption (UNCAC), GRECO and OECD. Regulations conflicts of interest and penalties vary across the EU. The level of control is relatively low, although Romania has independent agency that monitors conflicts of interest, their ability to cover the entire national territory and to monitor decisions is insufficient; others have established an ethics committee responsible for these checks to report to Parliament; checks on the members of Parliament are conducted in some cases by a parliamentary committee or, in other cases, by a commission responsible for investigating conflicts of interest and declarations of assets even though these courts often lack capacity and limited powers in sanctioning. Background checks often exist only on paper, limiting generally administrative controls. Capacity and monitoring tools required to perform substantial checks are often insufficient.

\subsection{Private Sector}

\subsubsection{Integrity and Transparency of the Financial Sector}

The need to strengthen standards on integrity and transparency in the financial sector was mentioned often by the financial crisis. A report by the Parliamentary Assembly of the Council of Europe establishes a link between "cases of high corruption" and evasion through offshore companies and tax havens. The report covers the initiative to recover assets stolen (StAR) launched by the World Bank and UNODC, which analyzed 150 cases of high corruption and found a direct link between corruption widely practiced by senior civil servants and concealing assets stolen through opaque shell companies, foundations and some of the trusts. In addition, it specified the obstacles encountered during the investigation and prosecution of stolen assets, due to lack of access to information on beneficial owners and use of complex corporate structures subject to multiple jurisdictions. In Romania, recent controversy involving the financial sector, including large banks and relate to matters such as fixing interest rates, irresponsible and speculative lending and a lack of diligence had raised concerns about regulatory and enforcement of existing rules. The role played by banks to facilitate or accepting money laundering has been widely debated. The project of creating a register of owners of companies registered publicly accessible should increase transparency.

\subsubsection{Giving or Taking Bribes Transnationally}

Romania encounters difficulties in regard to the behavior of foreign companies in our country, especially from countries where corrupt practices are widespread. OECD rigorously monitors this area, highlighting in its periodic evaluations, the results satisfactory and less satisfactory in terms of enforcement. There are best practices in this regard in several member states (the Nordic countries, Benelux). They may cover several aspects: a significant number of prosecutions concluded successfully applying harsh sanctions, the priority given to cases of giving or taking bribes transnational or recent adoption of a law exhaustive on 
combating this phenomenon in order to strengthen legal instruments and procedures to prevent and prosecute corruption offenses, especially regarding giving or taking bribes from the transnational level.

\subsubsection{Public Companies}

In Romania, the supervision of the state is poor: legislation in this area is unclear, and the politicization of appointments impedes merit and pursuit of public interest. In addition, there are insufficient guarantees or mechanisms to prevent corruption and sanctioning conflicts of interest. Allocating funds and, in some cases, the purchase of services by these companies are characterized by a low level of transparency. Recent investigations into alleged cases of misuse of funds, corruption and money laundering aimed SOEs indicate the high level of corruption risks in this area, as well as deficiencies in control and prevention.

\subsubsection{The Links between Corruption and Organized Crime}

In Romania, organized crime and corruption pose considerable problems that often serve to facilitate this type of crime. The links between organized crime groups and companies remain a concern, particularly at regional and local level and in terms of procurement, construction, maintenance services, waste management and other sectors. Overall, corruption remains a serious threat because it enables organized crime groups to infiltrate the private sector, as demonstrated Threat Assessment posed serious crime and organized crime in Romania (Serious Organised Crime Threat Assessment), made 2013 by Europol.

\subsection{Recommendations for Both Sectors}

\section{Lobby}

In the complex world of public policies, it is desirable for government to engage in an ongoing dialogue with external stakeholders. All interested parties should be able to express their opinion, but this should be done in a transparent manner. Given that lobbying may involve risks of corruption and biased regulations, it is desirable to adopt mechanisms to allow inclusion of these activities, either by legislation or by voluntary registration of lobbyists persons. These mechanisms may contribute to clarity and transparency in the relationship between public authorities and external stakeholders. As such, they can work to reduce the risk of corruption. Until now, this area has not developed enough, although Romania is in place or under development in this legislation or debating the possibility of introducing new mechanisms.

Implementation of strict standards of transparency for the entire procurement cycle and when performing the contract must be implemented:

- ensuring common minimum standards of transparency at regional and local administrations as regards procurement procedures and implementation phase of public contracts;

- examining ways of publishing or making available of public contracts concluded, including provisions on the rights, obligations and terms of penalty, 
unless they are necessary exemptions for reasons of confidentiality defined, limited and justified for certain contractual clauses.

Increase transparency of public procurement procedures, prior and subsequent award by publishing on the Internet by all administrative structures (central, regional and local) the annual accounts and balance sheets, and the situation broken down spending for public works, goods and services; ensuring greater transparency of procurement procedures carried out by state-owned enterprises and in the context of public-private partnerships.

\section{Conflicts of Interest}

The authors declare no conflicts of interest regarding the publication of this paper.

\section{References}

Arbogast, S. V. (2013). Resisting Corporate Corruption: Cases in Practical Ethics From Enron Through The Financial Crisis (2nd ed.). Hoboken, NJ: Wiley-Blackwell. https://doi.org/10.1002/9781118659069

Bowie, N. E., \& Werhane, P. H. (2004). Management Ethics. Hoboken, NJ: Wiley-Blackwell.

Boylan, M. (2013). Business Ethics (2nd ed.). Hoboken, NJ: Wiley-Blackwell.

Bratianu, C., \& Vasilache, S. (2009). Implementing Innovation and Knowledge Management in the Romanian Economy. Management \& Marketing, 4, 3-14.

Collins, D. (2012). Business Ethics: How to Design and Manage Ethical Organizations. Hoboken, NJ: Wiley-Blackwell.

Donaldson, T., \& Gini, A. R. (1990). Case Studies in Business Ethics. Upper Saddle River, NJ: Prentice Hall.

Flonta, M. (2002). Colaborare sau iesire din scena? Situatia dilematica a elitelor în regimuri dictatoriale ilustrata de cazul Heisenberg. Revista de filosofie, XLIX, 5-6.

Giles, S. (2015). The Business Ethics Twin-Track: Combining Controls and Culture to Minimize Reputational Risk. Hoboken, NJ: Wiley Publishing House

Hartley, R. F. (1993). Business Ethics: Violations of the Public Trust. Hoboken, NJ: Wiley-Blackwell.

Henn, S. K. (2009). Business Ethics: A Case Study Approach. Hoboken, NJ: Wiley-Blackwell.

Jeurissen, R. (2005). Moral Complexity in Organizations. In M. Korthals, \& R. Bogers (Eds.), Ethics for Life Scientists (pp. 11-20). Dordrecht: Springer.

Kaptein, S. P. (1998). Ethics Management. Auditing and Developing the Ethical Content of Organizations. Dordrecht: Springer. https://doi.org/10.1007/978-94-011-4978-5

Lefter, V., Dan, M. C., \& Vasilache, S. (2010). Statistical Analysis of the Evolution of Values in Human Resource Perspectives. Economic Computation and Economic Cybernetics Studies and Research, 44, 5-21.

McInnery, P. K., \& Rainbolt, G. W. (1994). Ethics. New York: Harper Perrenial.

Menzel, D. (2007). Ethics Management for Public Administrators. London: Sharpe.

Miroiu, A. (1995). Etica Aplicata. Bucharest: Alternative Publishing House.

Muresan, V. (2006). Filosofia morala a lui R. M. Hare. Bucharest: Paideia.

Newton, L. H. (2006). Permission to Steal: Revealing the Roots of Corporate Scandal-An 
Address to My Fellow Citizens. Hoboken, NJ: Wiley-Blackwell.

Rossouw, D. (2008). Practising Applied Ethics with Philosophical Integrity: The Case of Business Ethics. Business Ethics, the Environment and Responsibility, 17, 161-170. https://doi.org/10.1111/j.1467-8608.2008.00529.x

Rossouw, G. J., \& van Vuuren, L. J. (2003). Modes of Managing Morality: A Descriptive Model of Strategies for Managing Ethics. Journal of Business Ethics, 46, 389-402. https://doi.org/10.1023/A:1025645402328

Serban, D., Mitrut, C., Cristache, S. E., Epure, D., \& Vasilache, S. (2008). Intercultural and Inter-Confessional Relations in a Romanian Countryside. Journal for the Study of Religions and Ideologies, 7, 80-106.

Trevino, L. K., \& Nelson, K. A. (2014). Managing Business Ethics: Straight Talk about How to Do It Right (6th ed.). Hoboken, NJ: Wiley Publishing House.

Trevino, L. K., \& Weaver, G. (2003). Managing Ethics in Business Organizations. Palo Alto, CA: Stanford University Press.

Vasilache, S. (2010). The Relationship between Medical Literacy and Trust in Healthcare in Romania. Management \& Marketing, 5, 93-102. 